\title{
NEUROSES PROFISSIONAIS
}

NELSON PIRES *

Sem pretensões a inovar na nosologia psiquiátrica, acreditamos procedente a rubrica "Neuroses profissionais" tendo em conta a importância social do tema. A estadia recente de Mira y Lopez em S. Paulo veio avivar o valor da seleção e orientação profissionais. O presente estudo tem o sentido dum negativo fotográ fico das conferências de Mira y Lopez: vem mostrar o indivíduo debatendo-se em situaçōes desafortunadas no me:o profissional, situações que por vezes geram a constelação psíquica que vai provocar afinal reações anormais. Outras vezes se constituíram situações infelizes que vieram dar conteúdo psicopatológico às disposições anormais sôbre as quais agiram como escorva.

Kraepelin já falava de ponopatias referindo-se aos distúrbios mentais circunscritos aos misteres ocupacionais. Kraepelin foi ultrapassado por aquisições de tôda ordem: psicanalítica, constitucionalista, psicossomática e medicina integral. Não importa mais a nomenclatura, preocupação exagerada da psiquiatria antiga; mais importante é a compreensão total do distúrbio. Há mesmo, no distrito que estudamos, em certos casos, semelhanças extremas entre as neuroses do individuo e o que poderíamos chamar "neuroses sociais" - reações de reivindicação dos desprotegidos da fortuna - as greves proletárias, as revoltas mal sucedidas dos movimentos populares que ensejam novos ajustes ou novos conflitos com o poder. A psiquiatria clínica que estudou o indivíduo fornecerá, então, os informes necessários para compreender os casos coletivos de maior envergadura que ocupam o campo mais vasto da psiquiatria social.

O sentido geral dêste trabalho é polimorfo. Cada caso fere um aspecto determinado no quadro das relaçôes do indivíduo com o meio. Ora é suscitado um problema amplamente social — relações empregado-patrão - ora de sentido restrito assistencial - aposentadoria e reforma - ora

Trabalho apresentado à Secção de Neuro-Psiquiatria da Associação Paulista de Medicina em 6 agôsto 1945. Entregue para publicação em 8 agôsto 1945 .

* Docente de psiquiatria da Faculdade Fluminense de Medicina. Exassistente do Manicômio Judiciário do Rio de Janeiro. Capitão médico do Exército. 
exibe-se a necessidade imperativa da seleção profissional, ora é focalizado um reduzido problema e personalidade de indivíduo que, em qualquer ambiente, precipitaria sua caracterologia à procura duma ocasião para cristalizar as suas inferioridades, ora são demonstradas as afinidades íntimas entre situação e disposição psicopática, tão íntimas que desaparece tôda possibilidade de isolar, na produção mórbida final, a parte que cabe às constituições e a que cabe aos exógenos do ambiente. Cada caso oferece, portanto, um interêsse diferente dos denais. A sociedade moderna complicou-se tanto que a cada etapa que avan ̧a abre portas novas a aluviōes de problemas mórbidqs que se vão criando nas relações do indivíduo com o organismo coletivo ao qual pertence.

O diagnóstico pròpriamente dito não nos vai interessar. Não abordaremos a maçante questão de arrumação nosológica que tantas vezes parece, na moderna psiquiatria, mera exigência formalística ou burocrática a embaraçar a visão do problema total que foi extensamente analisado, compreendido e até resolvido com a compreensão. Mas no momento de apor o rótulo, em síntese, sôbre o material trabalhado, hesitamos em estabelecer a rubrica diagnóstica porque as exigências acadêmicas, por demais rígidas e pretenciosas, exigem violentemos sempre alguma coisa para que fique atendida a pragmática da nomenclatura que é, quase sempre, mutilante. Essas exigências acadêmicas e burocráticas não querem perder tempo com o diagnóstico polidimensional, única maneira correta de emitir um diagnóstico de verdade.

Finalmente, quero salientar que muitas neuroses profissionais são inevitáveis no atual estado de conhecimentos médicos, qualquer que seja - cuidado na orientação profissional e seleção de capacidades. Estes testes e provas não afastam as condições neurosogêneas que se criam, depois, no ambiente humano; êles não anulam, no homem selecionado $\mathrm{e}$ hábil profissionalmente, a capacidade de sentir e de sofrer as influências patogênicas ambientais.

Defendido o título do trabalho, passemos à sua substância.

J. M., com 35 anos de idade, casado, branco. Procura psiquiatra por sentir "cabeça vazia". inquietação, nervosismo, mal-estar indefinível, ansiedade; sente-se permanentemente aborrecido $\mathrm{e}$ indisposto, sem iniciativa, automatizado.

Empregado exemplar, guarda-livros de firma onde era interessado, começou a não poder executar seu trabalho com a correção habitual. Levantava-se de sua secretária pelo meio da tarde, saia a vagar sem destino, retornava ao emprêgo a horas incertas, ou abandonava o seu trabalho sem maiores explicações. Não tolerava o rádio, o barulho dos filhos nem o bulício das ruas; abandonara as práticas religiosas, deixara os divertimentos, impacientava-se fàcilmente com a espôsa e tornara-se, no dizer desta, irritável e desassossegado. Vida sexual normal e espôso fidelíssimo. Não há antecedentes neuróticos nítidos, nem psicopatas nem neuropatas. O médico procurado investigou superficialmente o caso e proporcionou-lhe 10 choques convulsivos. $O$ doente acusou algumas melhoras mas retornou ao mesmo estado ao cabo de poucas semanas. Veio à nossa consulta e verificamos tratar-se duma personalidade astênica com certa rudeza intelectual; uma das muitas 
formas da psicastenia de Janet. Ao cabo dalgumas análises percebemos que a grande maioria dos seus sintomas aparecera no decurso de suas atividades como empregado. Chamava a atenção, sobretudo, a absoluta independência que lhe adviera após a doença. Entrava e saia quando bem entendia, conquanto faltasse pouco. As férias extemporâneas repetidas, as estações balneárias eram usadas desembaraçadamente, apesar de seu feitio escrupuloso e minucioso. Pouco a pouco descobrimos graves conflitos que tinham como alvo o patrão e suas atividades. Este era uma personalidade ciclotímica, de feitio folgazão, que possuia amantes, empreendia com elas viagens de recreio, durante as quais gastava sem conta recorrendo de contínuo ao dinheiro de sua casa comercial, pouco zeloso da lisura dessas retiradas extras de dinheiro: seguidamente precisava de dinheiro que mandava buscar nos clientes de sua fábrica, descontando certa porcentagem do montante da dívida dêsses freguezes contanto que pagassem logo; encomendas com execução apenas iniciada eram cobradas com descontos altos. Com êsse regime anárquico de cobranças eram sonegadas no movimento da firma somas importantes que não figuravam na escrituração. Dessa forma, os vários interessados da firma deixavam de participar da totalidade dos lucros. Alguns empregados despediram-se. Nosso observado conluiou-se com dois outros empregados e tentou comprar a fábrica; quasc intimidou o patrão que, entretanto, amigável e humoristicamente, recolocou os auxiliares nos seus respectivos lugares. Mas bem depressa voltou aos gastos desordenados e às cobranças irregulares.

Foi então que começaram os padecimentos de J. M.. Astênico, incapaz de combate e de esclarecimentos francos, começou a sentir-se mal no emprêgo e, aos poucos, o distúrbio foi tomando feições somáticas - sentia-se inquieto e mal do estômago, do fígada, do abdome (talvez um psicanalista traduzisse com razão que o doente não podia tragar aquela situação). Fêz-se operar 5 vezes do estômago, apêndice, aderências. À quinta operação, o cirurgião descobriu, afinal, que se tratava dum neurótico e encaminhou-o a um psiquiatra.

Assim, a neurose profissional era arma de combate contra o patrão deshonesto. J. M. não se revoltava abertamente contra êste e não ajustava a situação inas também não prestava a colaboração que the era habitual. Caia no regime da não obediência "gandiana", do boycott, da greve neurótica. A conversão do conflito psíquico em sintomas somáticos realizava-se em domínios variáveis - palpitações, extrassístoles e angústia pré-cordial, úlcera péptica, borborigmas, "flatos", pontadas e adormecimentos em regiões diversas, tonteiras, cabeça vazia, nervosismo, apatia ou inquietação desordenada, insônia. Chamamos o patrão, que sempre protegera o empregado na enfermidade, e relatamos a interpretação do caso. $O$ patrão tinha também suas idéias a respeito e já vislumbrara algo. Entendeu-se com o empregado: fêz-lhe propostas de venda, aproximou-se mais dêle, aumentou-lhe fortemente o ordenado e a porcentagem nos lucros, convidou-o para pescarias e férias, assistiu-o mais de perto, reduziu ao máximo as retiradas clandestinas. Um ano depois o empregado estava tão ajustado no emprêgo que dispensou assistência médica.

Neste caso fica patente: $a$ ) - o desencadeamento duma neurose por ter um empregado descoberto deslises do patrão que o prejudicavam econômicamente. A astenia psíquica do paciente vedava-lhe a ab-reação, o protesto. Esta neurose manifestava-se em domínios somáticos provocando intervençōes cirúrgicas desnecessárias.

b) - a neurose desligou-se das causas diretas e, do domínio profissional, irradiou-se para o domínio somático. Aqui está uma belíssima demonstração do inconsciente de Freud. Não se trata do clássico 
recalcamento histérico que implica em resistências para manter inconsciente o fato indesejável. $O$ que se passa pode ser descrito, é nossa opinião, do seguinte modo: o doente enfrenta um problema cuja resolução exige coragem, iniciativa e disposição. Estas qualidades o doente não as tem; entretanto, os prejuízos reais continuam ocasionando malestar crescente, má vontade no trabalho e perda de estímulo. A autoscopia faz o resto. O doente surpreende seus sintomas e só pensa nêles porque é constitucionalmente astênico e tende às ruminações mentais. Mas não há recalcamentos ou repressões conscientes, nem os fenômenos de cancelamento comuns nas neuroses compulsivas. O doente desvia-se do assunto por uma questão de econonia de gastos afetivos. Gasidria demais energias se lutasse. Não gasta, mas continua a sentir o pêso dos prejuízos situacionais, o que the causa mal-estar e tira-lhe o estímulo no trabalho. Podemos entender isto com o auxílio de imagens humorísticas; suponhamos um andarilho em cujo sapato introduziu-se uma pedra que the estorva a marcha. Para andar recurva o pé, pisa geitoso e devagar, contrai o rosto com a dor; depois impressiona-se com a dor, com o pé em posição forçada e com o pisar defeituoso. Procura o médico sem mais cogitar da pedra no sapato mas pede que o médico corrija os padecimentos. Só não tirou a pedra do sapato porque é um distraído que não sabe mais que importância isso pode ter no seu mal. Doutrinàriamente não há aqui recalcamento, repressão, deslocamento ou cancelamento. No entanto, é um dos inconscientes de Freud. É inconsciente para o doente o nexo da casualidade psíquica entre aquilo que sabe - o prejuízo causado pelo patrão - e a insatisfação com a vida em geral, a neurose.

c) - resultou da neurose una vantagem - independência no emprêgo, férias, honorários sem tabela fixa - e um sentido - o boicott, o protesto, e não participação no trabalho; a isto poderíamos chamar a "greve neurótica".

d) - a astenia psíquica constitucional jamais manifestada paiològicamente mas entrevista nas atividades normais - o escrúpulo, a modéstia, a exatidão exagerada, a submissão até mesmo quando havia irregularidades a enfrentar, a incapacidade de luta, de ab-reações e depo:s, a sintomatologia hipocondríaca e até masoquística.

$\varepsilon)$ - as relações empregado-patrão poden, ser, portanto, neurosogêneas. $O$ mal-estar de muitas classes trabalhadoras assume, por vezes, uma linguagem reivindicadora que poderia ser traduzida como expressão da neurose social - o direito de greve, por exemplo. Assim co:no o indivíduo prejudicado que estudamos enveredou neuròticamente por êsse direito, também classes inteiras pugnam por êle. Então que se percebe a importância enorme da justiça do trabalho regulando as relaçóes empregado-patrão o promulgando doutrinas a respeito, sob a égide do Estado. 
f) - certas nuances do "ressentimento" tão extensamente analisado por Max Scheler são perfeitamente visíveis no observado teiado como alvo o patrão. Este ressentimento é que alenta grande parte das reivindicações das massas proletárias. Elas justificam tal ressentimento com apaixonados exames das injustiças sociais, codificando os renedios em doutrinas partidárias onde se racionalizou a reivindicação. E o ressentimento quem dá a estenia revolucionária aos slogans dos agitadores. ${ }^{1}$ De modo algum supomos que o ressentimento seja fator torvo ou injusto. Estamos procurando situar-lhe o travesti e a psicodinâmica.

A observação seguinte é exemplo duma neurose profissional onde preponderava a simulação e cuja evolução foi cortada de modo nítido pela intervenção do médico e pela capacidade estênica de luta do observado.

F. V., com 37 anos de idade, militar, aparece no hospital, queixando-se de "imrossibilidade de trabalhar, raciocinar, concentrar-se". Isto data de poucos dias. Ccmeçou por sentir-se abstrato, aparvalhado; seus companheiros observaram que o doente respondia às perguntas como si as não tivesse compreendido, reperguntava várias vezes o mesmo assunto, denotava uma fisionomia estúpida, olhando esgazeado para o teto ou para as paredes, vivia calado e "abobado" como que nerplexo com tudo o que ocorria em volta. Era totalmente inútil na repartição onde trabalhava. No passado mórbido não se registravam antecedentes neuro ou psicopáticos de qualquer espécie. Apuramos incidência de lues. Negava motivos compreensíveis capazes de tornar a doença inteligível.

Examinado, absolutamente nada se encontrou de anormal. Proposta a punção suboccipital, foi incontinenti aceita e realizada. Analisado o líquor, êste revelou-se negativo para lues. Não encontrando do ponto de vista somático sinal algum anormal e como era contestada qualquer razão para a doença, solicitamos sua baixa ao hospital, o que foi feito. Mais o observávamos e mais nos convencíamos da psicogênese da síndrome. $O$ doente vivia em dificuldades econômicas. mas isso já datava de muito tempo e até já se habituara a êsse regime. Resolvemos então devassar, sem que o doente o soubesse, sua situação na repartição onde trabalhava.

Foi-nos revelado confidencialmente que se estava processando uma devassa na repartição e que o doente estava "alcançado" em mais de 45 mil cruzeiros. A devassa era oficial mas sigilosa. Investigando, viemos a saber que alguém havia delatado ao doente o fato, embora o fizesse por alusões veladas. Datava daí a doença de F. V., conforme apuramos com tôda a minúcia cronológica. Retornamos ao hospital e de tudo demos parte ao doente. Como resultado vimos o estupor dêste manifestar-se em grau muito maior. Sem acreditar nisso propuzemoslhe obtivesse a soma para repor e resgatar o déficit; concitâmo-lo a entrar na realidade da situação de fato. O doente denotou certa surprêsa e, logo em seguida, tornou-se de novo aparvalhado, atônito, confuso, perplexo. o que the impedia de providenciar qualquer coisa. Chamamos sua companheira e novamente

1. O Lebensraum era uma manifestação de ressentimento contra a mutilação territorial metropolitana e contra a vastidã̃o dos impérios coloniais, de nivel insuportável à arrogância teuta. O "Ein Volk, ein Fuehrer", ressentimento contra a divisão da Alemanha, outorgando o destino das minorias alemãs à suzerania de outras nações. 
alvitramos que contraisse um empréstimo para cobrir o desfalque. A moça concordou e pediu prazo. No dia imediato e nos outros a seguir, o doente hospitalizado em "regime aberto" saiu à rua com a companheira, demorando-se muito. Retornava sempre visivelmente melhor e dizia-se grato à vitaminoterapia que lhe prescrevêramos com intuitos puramente sugestivos, fornecendo uma terapêutica qualquer que levasse o faltoso a não se sentir humilhado, coisa que se daria se nada the prescrevêssemos, procurando apenas focalizar a falta, o que eqüivalia a reputá-lo simulador puro e simples. Como essas melhoras deviam ter outra razão, solicitamos lealmente do doente os seus argumentos. Estes foram surpreendentes. Repelia a possibilidade dos desfalques subirem a tanto, porque revisara tôdas as suas atividades como tesoureiro e encontrara deslises de bem menor vulto. Não fugiria à responsabilidađe e ao balanço geral. Pediu alta do Hospital, obteve-a e saíu de repartição onde trabalhava depois de desafiar a prova de sua culpa muito mais que provável. $O$ inquérito prosseguiu, sempre comprovando as faltas de dinheiro sob a responsabilidade do nosso paciente. Aguardam fase judiciária. No entanto, há um ano o doente encontra-se integralmente bom.

Estupor neurótico ou estupor simulado? Parece que um e outro nascem do mesmo radical psicopático e que a separação absoluta é impossível, tratando-se antes duma questão de interrelação e não de proporcionalidade. Mas o distúrbio é inteiramente penetrável psicològicamente. Há, nas desordens dêste tipo, uma fase em que o indivíduo pode optar pelo refútgio neurótico ou pela realidade áspera com a vantagem da cura final. Di-lo Kretschmer e assim também depôs George Dumas quando relatou a experiência autobiográfica dum tremor pós-traumático de que foi vítima: podia, nessa ocasião, eternizá-lo com certos de artifícios hipertonização muscular - ou suprimí-lo. Possívelmente depois de certo tempo ocorreria a automatização e a "objetivação" (Kretschmer). Nesse momento em que tudo depende das ocorrências externas - o que Claude chamaria "momentos fecundos" - interveio o médico com a conduta preconizada por todos os autores que estudam a simulaçãı e que consiste em "fornecer uma porta de saída para o doente, sem acusálo de simulação." Não foi preciso eximí-lo de culpa, nem conseguir a soma faltante. O próprio doente encontrou o seu caminho, caminho que poderia ser outro qualquer - confessar, entregar-se à prisão ou fugir - mas sempre cam:rihos extraneuróticos. Traça-os a constituição e as condições de tôda ordem atuais vigentes: ambiente, oportunidades, estímulos eventuais, qualidade de assistência médica. Do ponto de vista terapêtutico, o resultado foi ótimo. E entretanto o doente era culpaco, a situação não se alterou e o inquérito prossegu:u.

Antes de passar ao seguinte caso, desejo intercalar duas observações curiosas e bem oportunas pelos motivos psicológicos evidentíssimos incluídos na gênese da neurose mas que escapavam à compreensão do doente. Um observado de Stekel queixa-se daquela sintomatologia que o autor rubricou como "parapatia ansiosa", destacando-se naturalmente a ansiedade e a inquietação. $O$ rapaz era caixa duma casa comercial. Não havia nada que salientasse a origem sexual nessa neurose, como aliás em tantas outras. As dificuldades de vida do observado eram, entre- 
tanto, visíveis. A intuição de Stekel lobrigou o motivo crucial da neurose: o conflito permanente entre os impulsos de satisfazer suas necessidades por meio do dinheiro confiado à sua caixa e a repressão moral dêsses impulsos criminosos. Um autêntico conflito psíquico sem intervenção de nada que fôsse sexual na patoplastia sintomática. O simples recurso cristão de "evitar as tentações", removendo o caixa para outras ocupações profissionais que não a tesouraria, destruiu a parapatia ansiosa. Escusado dizer que muitíssimas neuroses têm essa gênese: a situação especial do doente abriga condições e estímulos subtilmente maléficos para sua estabilidade psíquica; criam-se conflitos e depois o impasse neurótico, a ansiedade, o mêdo fóbico àquela situação que exaspera o conflito ou desloca-se para outras atividades psíquicas como no caso seguinte.

Doente nosso examinado há 3 meses. Trata-se dum “self-made-man" que, de simples soldado, alçou-se à condição de oficial contador dum ministério militar. Tem uma longa, obscura e heróica história de luta pela vida, sempre compensada pela incessante elevação de categoria social. Sua primeira comissão profissional foi a de servir numa repartição com a função de tesoureiro. A repartição já era celebrizada como "estopim que está prestes a estourar" correndo que nela teriam havido operações financeiras de vulto eivadas de vícios, senão de irregularidades. Atribuia-se, anônima mas insistentemente, aos antecessores de nosso observado altas transaçōes menos corretas. O temperamento estênico de nosso observado fê-lo aceitar assim mesmo a missão, comprometendo-se êle tàcitamente a arcar com tôdas as responsabilidades, pois que não denunciou o que se passava, ao receber o movimento de dinheiro. Durante muito tempo desdobrou-se em atividades, esgrimindo com todos os recursos profissionais e físicos de que dispunha. Aos poucos se foi vendo emaranhado na situação. Perdeu o sono, a euforia antiga desapareceu, tornou-se deprimido, intranqüilo e sem capacidade de atentar ou de produzir grande coisa; tornou-se sexualmente frio. Não podia pedir férias porque the dariam um substituto interino que talvez não aceitasse aquêle statı quo e denunciasse tudo. Entrara nosso doente na conivência criminosa pois que, por solidariedade de classe, procurara encobrir o que era irregular, dando prosseguimento ou legitimidade a vícios administrativos de seus companheiros antecedentes. Procurou médico, pedindo que the desse estimulantes para vencer sua improdutividade, fois precisava recuperar o antigo vigor mental para vencer duras tarefas c arrumar as coisas.

Preparando-o convenientemente, fizemos-lhe 5 choques convulsivos e intensa psicoterapia no sentido de dar-lhe ânimo para contornar o impasse, pleiteando que os superiores aceitassem o estado atual de coisas e o ajudassem a passar adiante a fração de problemas que êle não pudera resolver. Grande melhoria inicial e novo elan de esfôrço, que foi arrefecendo devagar. Ultimamente voltara a hesitar e a temer. Propuzemos-lhe, então, a solução direta: armar-se dos documentos possíveis, inventariar o histórico da administração e abordar francamente o assunto com os superiores. O doente já estava a pensar em demitir-se do ministério ou em solicitar licença de qualquer maneira e sair do cargo. Por motivos que não vêm ao caso, não pude saber o resultado final, qual das três decisões tomou o dornte e qual a solução da neurose, inicialmente de estrito âmbito profissional mas mais tarde substituída por sintomatologia neurótica. Já o doente não sabia que a doença derivava duma situação crônicamente exasperante, insolúvel sem luta; só prestava atenção aos resultados da tensão afetiva cronificada e que eram os sintomas psicopáticos.

Neurose profissional de tipo inteiramente diversa é a que se segue:

S. R., com 43 anos de idade, branco, casado, oficial superior do Exército. Vem à consulta queixando-se de que sua capacidade de trabalho decai dia a dia, 
não tem disposição para acometer as tarefas pelas quais é responsável, sonolência pesada após as refeições e insônia à noite, ansiedade, instabilidade e excitabilidade. Grande cerimonial para poder iniciar o serviço burocrático; sem liqüidar um assunto acomete outro. Explicações infindáveis sôbre suas dificuldades de trabalho - demora horas a discriminar o que pode e o que não pode fazer, as vivências associadas, fazendo praça de dizer que "tem confiança em si mesmo", tem experiência e desenvoltura nas decisões, jacta-se de ter "tarimba", que the permitiu sempre "sair das entaladas" airosamente. Ao começar o trabalho cotidiano sente repugnância quase fóbica pelo serviço, sobrevem uma "preguiça mental" invencível e por isso acredita-se "apoucado mentalmente", faltando-lhe idéias diretrizes que lhe permitam decidir da solução de papéis. Percebe-se que há sintomas extraordinários: toma das mãos dos auxiliares todos os papéis a resolver e avoca-os a si por ser "o chefe e o mais capaz". Todavia êsses mesmos papéis acumulam-se com os demais, sem solução. Diz que "só se sente bem em casa, onde é inteiramente feliz". Não dorme "porque preocupa-se eternamente com o serviço, o atrazo em que se acha êste e pensa nas soluções que deve propor a certos problemas"; procura resolver à noite o que deixara de resolver de dia e imerge na insônia ideatória. Faz alarde de sua saúde física para admitir, daí a pouco, que "tudo isto pode ser do fígado". Vida sexual normal. A sintomatologia foi atendida com psicoterapia, exercícios físicos, banhos frios, sedativos à noite e hormônio testicular (visando apenas os benefícios de euforia e estimulação psíquica). Com alternativas, o doente chega quase à cura.

Neste interim, afasto-me do doente por motivos involuntários, ficando êle sem assistência médica durante um mês. Ao cabo dêsse tempo recebo ordem de examiná-1o "por terem aparecido manifestações psicóticas graves": o doente ora delirava, ora mostrava-se atônito, apático, vagueando em sua casa a monologar infindàvelmente, com a estereotipia verbal "papéis, quantos papéis"; chorava por nônadas, passava horas seguidas no leito em aparente estupor que impedia de todo a conversação com seus amigos e com a espôsa, hebetamento alternado com extrema inquietação que subia a agitação. Interrogado, ou "não compreendia" as perguntas e calava-se, ou respondia algo desencontradamente; outras vezes ficava a repetir "papéis, doutor, só vejo papéis". Ao examiná-lo naquela fase ainda branda da síndrome, percebendo que sua neurose circunscrevia-se apenas às atividades profissionais (os sintomas que apareciam em casa decorriam da preocupação com assuntos profissionais), inqueri do doente o estado em que se encontrava o serviço e soube-o atrazado. Dadas as condições psíquicas do observado, propuz-lhe dar ciência de todo êsse atrazo à autoridade competente, solicitando-lhe auxiliares. Respondeu-me "que tinha muito brio para chegar a isso, além de que era perfeitamente capaz de solucionar tudo, pois que sempre o fôra em transes análogos". Proponho-lhe licença para tratamento de saúde e nosso observado também "não deseja transmitir a nenhum colega as dificuldades em que se acha o serviço pelas quais sente-se o único responsável". Assim não há margem para um desenlace satisfatório e efetivo. Nos antecedentes há um episódio histérico: dispnéia intensa sem qualquer distúrbio cardiovascular ou pulmonar e sem sinal de asma; apenas a respiração ruidosa mas livre dizendo que a fricção no epigástrio aliviava-o. Dois competentes profissionais que o assistiram verificaram ser o espetaculoso acidente de natureza histérica, remitindo com psicoterapia armada. Interrogando, a fundo, o doente e pessoas de seu ambiente, venho a saber que a síndrome agravara-se a partir dum acontecimento bem determinado: o seu superior hierárquico tivera notícias de seus sintomas, lastimara-o, condoera-se dêle e alvitrara uma doença, supondo que tudo derivasse da surmenagem. Ao saber que seu superior lançara as vistas sôbre seu caso, S. R. não compareceu, desde o dia seguinte, à repartição, pois que piorara. Redobraram também seus temores de uma inspeção; vislumbrava contudo uma solução final para tanta tensão: a si- 
tuação angustiosa ia decidir-se. E como o comandante lastimara-o, a reação neurótica manifestava-se agora num agravamento: passou a delirar sôbre temas de profissão, jazia prostrado na cama dias inteiros e tornara-se incapaz de conversas com os visitantes.

Alvitrei que outra pessoa se encarregasse de despachar o expediente atrazado, atualizasse todos os papéis dependentes de solução; depois disso, remoção do doente para outra chefia. $\mathrm{Em}$ poucos dias isto foi feito, verificando-se haver tal atrazo no expediente que até, por exemplo, selos que deveriam ser remetidos, haviam demorado tanto tempo na repártição que já se tinham tornado caducos. Nenhuma falta de dinheiro e nenhum extravio de papéis, apenas enorme atrazo de mais de ano e meio nos despachos, desordem na administração, confusão no encaminhamento de documentos. A remissão foi rápida. Em alguns dias tudo desapareceu, sobrevindo a saúde habitual. Neste caso nem sequer empregamos, na fase grave, a terapêutica psicossomática. Terapêutica psicológica pura e simples.

Este paciente tem aquela personalidade que alguns psicanalistas chamam captativa (Hesnard), retentiva — tudo retêm para exame meticuloso e infindável, exagerada consciência de seu próprio valor como indivíduo preciso, exato, insubstituível. Evidentemente trata-se de pessoa ciosa de sua autoridade, eficiência e probidade. Ao lado disso, vulnerabilidade à fadiga, à tensão afetiva quando esta se prolonga um pouco, aos sentimentos de responsabilidade, apesar de alegar sua capacidade de vencer e resolver tudo. Disso resulta que propôs-se tarefa superior a suas fôrças; por orgulho não licenciou-se ou pediu auxílio quando o fracasso se desenhou, não tolerou que se desconfiasse dêsse fracasso e assim tornou impossível a solução real e comum. Alguns traços, pois, dos sensitivos de Kretschmer, em mistura com outros dos primitivos que êsse autor esboçou no "Zusammengesetzte charaktere", os caracteres compostos. O resultado final é uma reação mixta histérico-sensitiva e não um delírio de relação. Talvez se houvesse realmente a temida inspeção e esta revelasse o atrazo no serviço, atrazo advindo apesar de ser trabalhador infatigável, só devido ao seu feitio psíquico, então a devassa configuraria o específico trauma da "beschämende Insuffiziens", insuficiência humilhante, e a reação psicopática seria outra - o delírio de relação. Assim ensina Kretschmer.

E interessante aquele sintoma: antes de começar o trabalho sente repugnância quase fóbica pelo gênero de serviço. Justamente o mecanismo psicopatológico da fobia que Freud estabeleceu no "Hemmung Symptom und Angst": montam-se defêsas - a angústia fóbica - diante de tudo que é perigoso. No caso, o perigoso é o serviço atrazado que atrai angústia de culpa e receio de punição. Surge o "horror ao trabalho" e isto toma significado e conteúdo doentio porque êstes indivíduos tendem mesmo a "refugiar-se na doença" seja porque são constitucionalmente propensos a evadirem-se da luta (Kretschmer) seja porque a sua censura aceita melhor a desculpa da doença que a de desmazêlo ou de incapacidade (Adler), seja porque, aceitando a doença, evitam a punição (Ferenezi). O fato é que a origem do atrazo deriva dos compo- 
nentes neuróticos de exageradamente reter e examinar, pelo absorvente da sua posição de chefe omnividente, capaz de tudo resolver e incapaz de confessar ou atender à propria insuficiência. Esta faceta da personalidade explica os traços compulsivos - tirava das mãos dos auxiliares todos os papéis e avocava-os a si. Mas não as resolvia. Destarte suprimia o ensêjo de verificar que outros resolviam aquilo que êle proprio era incapaz de solucionar.

Finalmente, a piora grave da última fase, instalou-se com motivos evidentes: $a$ - temor e vergonha ante a inspeção iminente; $b$-vontade de incompatilizar-se definitivamente com tal serviço, apregoando a preocupação excessiva com êle, sem confessar a incapacidade; $c$ - eximir-se de culpa mediante o refúgio na doença. O conteúdo do "delírio" é tão temático (só vejo papéis), que leva até à suspeita de simulação. Digna de menção ainda é a pronta cura, logo que foi dissolvida a situação difícil. Os sintomas que aparecem fora do âmbito profissional - insônia e inquietação - decorrem da preocupação com os problemas profissionais.

Quanto à surmenage, é necessário revisar o papel que lhe cabe, pois que é sempre fácil e cômodo reputá-lo fator patogênico. Julgamos que a surmenage só é morbígena quando sôbre ela se enxertam fatores afetivos, quando coexiste grande responsabilidade e temor, surmenage com conflitos psíquicos de tôda ordem, surmenage em esforços competitivos. Só então, quando, ao lado da exaustão, existe uma tensão afetiva, a exaustão é patogênica. Bleuler diz mais ou menos o mesmo com outra autoridade.

Enfim, no inventário desta neurose profissional, encontramos: Ifeitio de personalidade mixto sensitivo-primitivo que, com as retençóes e coartamentos, criou impasses na boa administração. Daí veio a situação difìcilmente superável para tais temperamentos; 2- reação psicopática com a sintomatologia da antiga psicose histérica, hoje quase na excomunhão doutrinária, mas que é uma realidade clínica por vezes aparentada intimamente com a síndrome de Ganser.

Nestas reações notamos: a- um sentido: incompatibilizar-se com aquêle serviço; b- uma vantagem - eximir-se da culpa do mau serviço e eximir-se de confessar a incapacidade administrativa. Dando-se como "mártir do trabalho", imputou à doença o fracasso na chefia e fêz portanto uma auto-afirmação socialmente inútil (A. Adler). Personalidade dêste tipo nas posições de direção e responsabilidade podem desajustar-se com relativa facilidade.

Neurose gravíssima, com desfêcho trágico, é o que exemplifica o caso seguinte:

A. A., com 42 anos de idade, casado, oficial superior. Tem longa história de psicastenia que até nas atividades normais imprime sua nota própria: timidez excessiva, humildade, minúcia, exatidão, escrupulosidade e pavor à responsabilidade. 
Males físicos de que se queixa são patognomônicos: cabeça ôca, falta de acuidade mental, fraqueza de idéias, irresolução, preocupação permanente com os deveres, dúvida se os executou bem, adiamentos de ação ("peur de l'action", de Janet). Um ano antes da doença atual, por ter de assumir a chefia do serviço, ficou em tal estado de pânico que procurou insistentemente médico e acabou baixando ao hospital durante cêrca de 20 dias até que chegasse o chefe legítimo. Isto valeu-lhe grande atrazo na promoção, fato de seu pleno conhecimento e que surpreendeu grandemente os companheiros. Com isso sofreu numerosas preterições de colegas que passaram a sua frente, definitivamente, no resto da vida profissional.

No hospital foi detidamente examinado; seu feitio psicastênico era tão pronunciado e tinha tal horror às decisões e responsabilidades que, no exercício da profissão, um pedido banal de rotina era alvo de especulações, hesitações, considerações sem fim para, ao têrmo disso, evitar de atender. Cumprimentava com excesso de respeito qualquer subordinado; se estava na chefia interina do serviço, telefonava incessantemente para o estrada de ferro e para o aeroporto a saber se seu substituto efetivo já havia chegado da pequena viagem que empreendera. Evitava receber o material que iria ficar sob sua responsabilidade, examinava e reexaminava obcessivamente tôdas as obras que devia fiscalizar. Tremia ao pensar que seus cálculos podiam estar errados e refazia-os incessantemente. Ao entrar na repartição indagava disfarçadamente "se nada havia contra si", admitindo sempre uma censura ou um êrro seu, evitava falar com seus superiores, a quem temia sôbre tôdas as coisas. Ao dirigir a palavra a alguém, pedia desculpas pela interrupção que causava, falava baixo e com inúmeras mesuras, excessos de delicadeza e até submissão descabida. Para o lar levava tôdas as preocupações profissionais. Insônia alternada com certa agitação ansiosa. Julgava que sua incapaciadde intelectual (tivera várias vezes primeiro lugar nos cursos e concursos) era por todos notada, senão mesmo comentada e testada. Percebia-o nas alusões, nos reparos e olhares de que era alvo. Supunha-se incompetente e duvidava de tudo o que fazia. Com a chegada do chefe e com incitações de última hora feitas para que não perdesse a promoção, pediu alta do hospital, conquanto já fôsse excessivamente tarde para evitar as preterições.

Medicado intensamente, auxiliado por fisioterapia e assistência psicoterápica, o doente superou êste surto por algum tempo. Promovido afinal, chegara sua vez, um ano após, de ser chefe. A sua alta patente caberiam daí em diante funçōes de comando ou direção. Retornaram os antigos sintomas de incompatibilidade com as funções de chefe; como se tornassem agudíssimos, procurou meu consultório, onde lhe expus a única solução para o caso, a saber, a reforma pois que, dêste modo, estaria para sempre afastada a principal causa determinante de seu desajustamento mórbido. Detalhada mas cuidadosamente the foi explicado que tal medida, sem ter qualquer inconveniente, tira-lo-ia de dificuldades imediatas e remotas. Após considerações supérfluas, fruto ainda da neurose - incapacidade de decisão, irresolução - deixou de aceitar a drástica medida. Preferia a solução estritamente medicamentosa. Recomeçamos o tratamento opqterápico, educação física, estimulantes gerais, regime adequado de trabalho, dividindo as tarefas racionalmente, vencendo-as uma por uma e, tal como seu feitio meticuloso o exigia, alternativas de trabalho e repouso, disciplina e diversões, tudo nos moldes de Kretschmer, psicoterapia não psicanalítica (o doente analisava-se demais), revezando isso tudo com balneoterapia e sedativos neurovegetativos. $\mathrm{E}$, como resultasse inútil essa massa de medidas, alvitrei, como recurso desesperado, a convulsoterapia. O doente aceitou-a no dia da proposta, mas recusou-a no dia imediato alegando que sua espôsa opusera-se a ela. E de notar que nenhum dos dois conhecia tal tratamento nem lhe havíamos dito nada; ao contrário, preparáramos o doente para receber em favorável terreno as surprêsas que iria ter quando retornasse a si " já inteiramente curado" e coisas semelhantes. Não retornou à consulta, possìvel- 
mente envergonhado de sua própria indecisão. Algumas semanas mais tarde, suicidou-se por enforcamento.

Neste caso, a neurose profissional é apenas o aspecto manifesto duma personalidade psicopática astênica com sintomas anancásticos e sensitivos de relação, muito vizinhos dum mesmo radical psicopático. Eis os traços caraterísticos dêsses sensitivos: elevada sensibilidade moral, vulnerabilidade extrema aos sentimentos de responsabilidade, ao lado de boa dose de ambição (obteve vários primeiros lugares com inaudito esfôrço, pois que a inteligência não era tão brilhante), timidez, insegurança, escrúpulo excessivo e, depois da doença, quase um delirio de relação (era percebida e comentada a sua incapacidade). Mas esta psicastenia nunca teve conteúdos que não fôssem atinentes a sua profissão e, além disso, o doente sempre tolerou os diversos surtos neuróticos enquanto tinha funções subalternas. Quando devia assumir cargos de direção, agravou-se de tal maneira a síndrome que não encontrou mais possibilidades de resolvê-la a não ser pelo suicídio. Os postos de mando e direção, o aumento de responsabilidade eram o estímulo específico ou, como muito se usava dizer antigamente, a espinha irritante do sistema psicopático.

Não é possível fazer muita coisa por êstes doentes, a não ser retirá-los da tensa situação que alimenta a neurose. No caso, seria a reforma por motivos de saude, e esta foi repelida por motivos de vergonha excessiva, ainda da constelação do escrúpulo psicastênico. Muito menos dramática seria a neurose se, mediante provas de seleção mental, êste doente fôsse impedido de ingressar numa profissão que iria exigirthe precisamente aquilo que êle não tinha: espirito de decisão, capacidade de mando e destemor a responsabilidade. Neste caso, a neurose profissional do tipo psicastênico foi deflagrada pelo desajustamento entre as caraterísticas da personalidade e as solicitações do ambiente. Muitas vezes se preconisa para os neuróticos a "cura de endurecimento", modalidade disciplinar que os reconduziria à normalidade; assim agindo deixamos sempre uma leve supeita de ilegitimidade no sof rimento neurótico. Mas aqui aparece justamente o oposto: o individuo assoberbado por estímulos que lhe solicitam adaptações acima de suas fôrças. São casos desta ordem que bradam pela implantação da seleção psicológica em nossas escolas militares, apesar de difícil o despistamento de anomalias mentais puramente neuróticas quando o exame é feito em grandes massas de alunos. Mas se é difícil o despistamento no ingresso é, entretanto, aí que se há de fazê-lo, porque o militar, para ser julgado incapaz, terá de arrostar uma infinidade de inconvenientes dos quais o menor é a pecha de psicopata e isto quando encontra médicos compreensivos que aceitam como reais as delicadezas inerentes aos problemas dos nervosos e dos desajustados.

Hospital Militar - Salvador (Brotas) - Bahia. 